\title{
Pelatihan Office Berbasis Cloud Sebagai Pendukung Administrasi RW di Perumahan Pondok Rhabayu Kota Batam
}

\author{
Nopriadi ${ }^{1}$, Erlin Elisa ${ }^{2}$ \\ 1Program Studi Sistem Informasi , Universitas Putera Batam, Batam \\ 2Program Studi Sistem Informasi, Universitas Putera Batam, Batam \\ Email: $\underline{1 \text { nopriadi.jamil@gmail.com, 2erlin_elisa@yahoo.com }}$
}

\begin{abstract}
Abstrak
Office berbasis cloud merupakan layanan aplikasi perkantoran dimana aplikasi yang dijalankan tanpa harus diinstal diperangkat komputer pengguna. Untuk menggunakannya, perangkat pengguna harus terhubung ke internet agar bisa mengakses server penyedia layanan cloud. Pada pengabdian ini, dilakukan pembinaan mengenai salah satu aplikasi berbasis cloud yang dapat digunakan untuk administrasi Rukun Warga (RW) di Perumahan Pondok Rabayu yaitu google docs. Google docs merupakan sebuah aplikasi yang fungsinya hampir sama dengan Microsoft Office keluaran Windows namun memiliki beberapa kelebihan yang tidak dimiliki oleh microsoft office. Data yang dikelola di google docs ditampilkan secara online, dapat di akses kapan saja dan dari mana saja serta bisa di shared (dibagikan untuk diakses dan dikelola bersama-sama). Tujuan penggunaan aplikasi ini adalah membantu Perangkat RW dalam pembuatan surat menyurat maupun laporan. Pembinaan ini dilakukan dengan memberikan materi kepada perangkat RW perumahan Pondok Rabayu, kelurahan Tembesi, kecamatan Sagulung, Batam dengan penyampaian yang mudah dan sederhana sehingga mudah diterima dan dapat menggunakan aplikasi tersebut dengan baik. Selain itu, pembinaan ini dilakukan agar perangkat RW Pondok Rabayu dapat memanfaatkan teknologi informasi dengan tepat dan terciptanya penggunaan teknologi informasi secara optimal di kehidupan masyarakat. Hasil yang diperoleh dalam pengabdian ini adalah peningkatan keterampilan perangkat RW perumahan Pondok Rhabayu dalam menggunakan aplikasi berbasis cloud dalam hal ini google docs yang digunakan untuk kegiatan administrasi RW.
\end{abstract}

Kata Kunci: Cloud, google docs, perumahan Pondok Rhabayu, administrasi RW.

\section{PENDAHULUAN}

Teknologi saat ini berkembang dengan pesat, tidak terkecuali dengan perkembangan dari teknologi informasi. Teknologi informasi sengaja diciptakan untuk memberikan kemudahan pada penggunanya dalam menyelesaikan tugas sehari-hari. Teknologi informasi kini menjadi pendukung utama aktifitas manusia. Aktifitas yang dilakukan akan menjadi lebih efesien dan dapat diselesaikan dengan cepat. Penggunaan teknologi informasi baik di komputer maupun smartphone, dapat kita lihat pada banyaknya aplikasi-aplikasi pendukung yang menawarkan berbagai kelebihannya.

Cloud computing computing atau dalam Bahasa Indonesia disebut komputasi awan adalah gabungan pemanfaatan teknologi komputer (komputasi) dan pengembangan berbasis Internet/awan (Fajrin, 2012). Pendapat lainnya menyatakan bahwa Cloud computing adalah sebuah model komputasi/computing, dimana sumber daya seperti 
processor/computing power, storage, network, dan software menjadi abstrak dan diberikan sebagai layanan di jaringan/internet menggunakan pola akses remote (Purbo, 2012). Pendapat yang lainnya juga menyebutkan bahwa cloud computing adalah sebuah konsep teknologi yang memungkinkan para pengguna komputer atau user menggunakan produkproduk IT dalam sebuah service (Tutang, 2014). Dari beberapa pendapat tersebut dapat disimpulkan bahwa teknologi cloud computing adalah sebuah teknologi yang menyediakan banyak layanan baik infrastruktur maupun aplikasi yang dapat diakses lewat jaringan internet.

Salah satu aplikasi office berbasis cloud adalah google docs. Google Docs merupakan salah satu aplikasi perkantoran online buatan google yang memungkinkan pengguna melakukan pengolahan berbagai dokumen teks, spreadsheet, maupun presentasi dimanapun (Wahana Komputer, 2010). Dengan adanya google docs pengguna hanya memerlukan komputer dengan sistem operasi apasaja, web browser dan yang tak kalah penting adalah jaringan internet. Selain itu, pengguna juga dapat menyimpan dokumen tersebut secara online sehingga pengguna tidak perlu membawa media penyimpanan portable kemana mana.

Perumahan Pondok Rhabayu kelurahan tembesi Kecamatan Sagulung, terdapat sebuah sebuah RW (Rukun Warga) yaitu RW 19 yang dikepalai oleh bapak Muljas dan beberapa perangkat RW lainnya. Di RW 19 ini terdapat beberapa RT(Rukun Tetangga) yang dikepalai oleh Kepala RT dimana masing - masing RT terdiri dari 80 - 120 Kepala keluarga(KK).

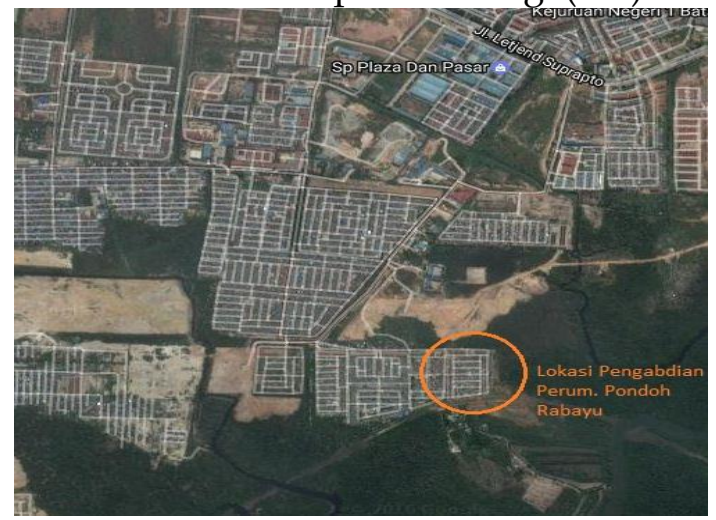

Gambar 1. Lokasi Pengabdian
Perangkat RW 19 ini berasal dari berbagai latar pekerjaan dan jam kerja yang berbeda - beda. Sehingga, menyulitkan bagi warga yang ingin mengurus administrasi ataupun dokumen - dokumen seperti surat domisili ataupun sejenisnya karena perangkat RW sering tidak berada di tempat. Keadaan ini juga menyulitkan bagi perangkat RW ketika akan mengadakan pertemuan karena susahnya untuk mengumpulkan perangkat RW yang ada. Selain itu, keterbatasan biaya juga menjadi salah satu permasalahan ketika perangkat RW memutuskan untuk menggunakan aplikasi yang legal. Ketika akan menggunakan aplikasi office, banyak penyedia aplikasi yang tersedia mulai dari yang offline sampai yang berbasis cloud sehingga membingungkan. Mulai dari yang gratis sampai yang berbayar memberikan fitur yang berbeda - beda sehingga membuat perangkat RW sendiri belum tau mana yang cocok atau sesuai dengan kebutuhan. Selain itu ada banyak sekali media dan aplikasi penyimpanan yang bisa di manfaatkan baik yang bersifat offline maupun secara online dan berbasis cloud dengan berbagai kelebihan dan dan kekurangan masing - masing sehingga membingungkan. Dan terakhir fitur yang diberikan di masing - masing aplikasi office berbeda - beda sehingga menimbulkan kesulitan dalam penggunaannya. Oleh sebab itu perlu diadakan pembinaan tentang hal ini.

Diharapkan dengan adanya pengabdian ini dapat memberikan bekal keterampilan bagi ketua RW beserta perangkat RW 19 perumahan Pondok Rhabayu sehingga terciptanya tertib administrasi dilingkungannya.

\section{METODE PELAKSANAAN}

Untuk menunjang pembinaan yang dilakukan tersebut supaya berjalan dengan sukses dan lancar maka dibutuhkan beberapa peralatan yang nantinya akan digunakan antara lain adalah Laptop Samsung Core i5, Modem Internet, Diktat, Video tutorial penggunaan aplikasi google docs. Ceramah, eksperimen, diskusi dan tanya jawab merupakan metode yang digunakan dalam kegiatan ini.

Metode pelaksanaan kegiatan serta penjelasan tahapan atau langkah-langkah 
dalam melaksanakan solusi yang ditawarkan untuk mengatasi permasalahan sebagai berikut:

1. Kegiatan pemilihan aplikasi yang akan digunakan.

Berikut ini adalah daftar kegiatan yang akan dilakukan:
a. Pengenalan tentang teknologi yang ada saat ini.
b. Pengenalan jenis - jenis aplikasi office.
c. Kelebihan dan kekurangan masing - masing aplikasi office.
d. Pemberian petunjuk pemilihan aplikasi.
e. Pelatihan pemilihan aplikasi yang sesuai kebutuhan.

2. Kegiatan pemilihan aplikasi penyimpanan.

Berikut ini adalah daftar kegiatan yang akan dilakukan:
a. Pengenalan tentang jenis - jenis aplikasi penyimpanan.
b. Kelebihan dan kekurangan masing - masing aplikasi penyimpanan.
c. Pemilihan aplikasi yang cocok untuk penyimpanan.
d. Pendaftaran email.
e. Pelatihan menggunakan aplikasi penyimpanan.

3. Kegiatan Cara menggunakan aplikasi Office.

Berikut ini adalah daftar kegiatan yang akan dilakukan:
a. Pelatihan pembuatan dokumen yang dibutuhkan untuk kegiatan administrasi Rukun Warga dengan google document.
b. Pelatihan pembuatan spreadsheet yang dibutuhkan untuk kegiatan administrasi Rukun Warga dengan google spreadsheet.
c. Pelatihan cara sharing dan berbagi pakai dokumen.

Untuk mengukur sampai sejauh mana penguasaan materi yang telah diberikan, maka perlu dilakukan evaluasi. Partisipasi peserta dalam pelaksanaan program sangat diharapkan sehingga penerimaan pembinaan akan semakin lancar. Adapun evaluasi pelaksanaan program yang keberlanjutan setelah selesai kegiatan pengabdian ini dilaksanakan antara lain.

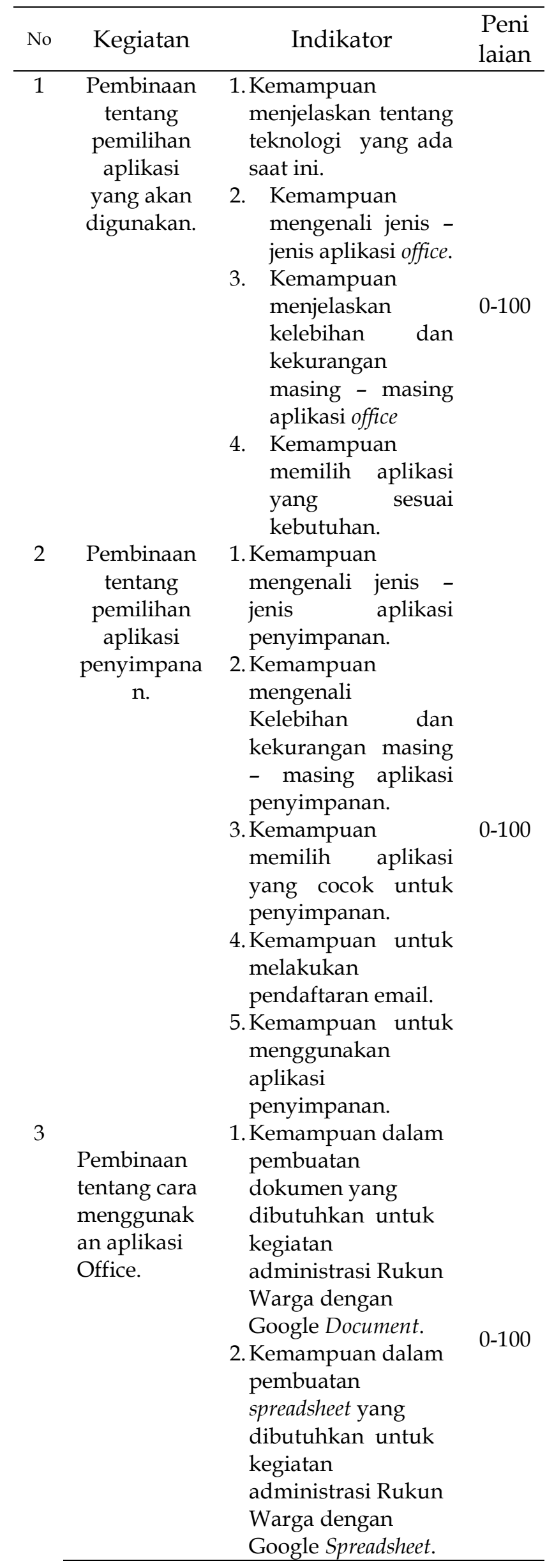




3. Kemampuan dalam
men-sharing
$\begin{aligned} & \text { berbagi } \\ & \text { dokumen. }\end{aligned}$

\section{HASIL DAN PEMBAHASAN}

Pelaksanaan pengabdian kepada masyarakat berjalan sesuai dengan apa yang telah direncanakan sebelumnya. Berikut merupakan pembahasan materi dari hasil pengabdian kepada masyarakat yang telah dilaksanakan.

1. Hasil dari pembinaan tentang pemilihan aplikasi office yang akan digunakan. Berdasarkan pengamatan yang telah dilakukan oleh pengabdi, peserta pembinaan telah memiliki pengetahuan tentang teknologi yang ada pada saat ini, peserta juga dapat menyebutkan jenis jenis aplikasi office yang yang ada pada saat ini, kelebihan dan kekurangan dari masing masing aplikasi dan menentukan aplikasi office yang sesuai dengan kebutuhan.

2. Hasil dari pembinaan tentang pemilihan aplikasi penyimpanan. Peserta pembinaan mampu mengenali jenis jenis aplikasi penyimpanan, menjelaskan apa yang menjadi kelebihan serta kekurangannya, mampu memilih aplikasi penyimpanan yang sesuai dengan kebutuhan. Selain itu peserta juga memiliki kemampuan untuk membuat akun email dan bisa menggunakan aplikasi penyimpanan.

3. Hasil dari pembinaan tentang cara menggunakan aplikasi Office berbasis cloud. Peserta pembinaan mampu membuat beberapa contoh surat maupun beberapa dokumen lainnya untuk kegiatan administrasi RW menggunakan google document, selain itu peserta pelatihan juga mulai mengerti tentang penggunakan google spreadsheet. Selain itu, peserta pembinaan juga bisa menggunakan fitur sharing dan berbagi pakai dokumen yang ada di google docs.

Saat ini selain memiliki kemampuan pembuatan dokumen, peserta pembinaan juga membuat beberapa akun email yang nantinya akan dipergunakan oleh perangkat RW untuk kegiatan administrasi RW.
Setelah pengabdi memberikan materi yang berkaitan dengan pembuatan dokumen, penggunaan spreadsheet dan cara sharing serta berbagi pakai dokumen melalui beberapa video dan mencoba langsung menggunakan google docs maka peserta pelatihan di anggap mengerti dan sudah bisa menggunakan aplikasi google docs. Hal ini di buktikan dengan beberapa dokumen yang berhasil dibuat peserta di google document dan di simpan di google drive:

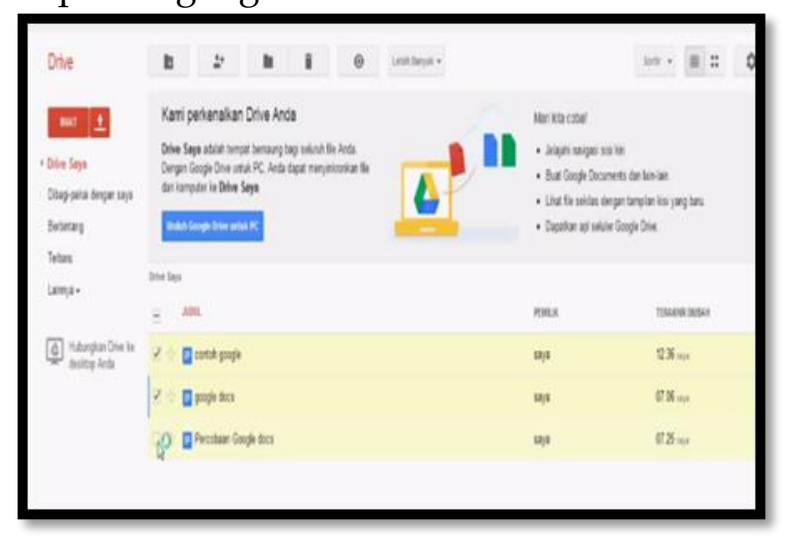

Gambar 2 menunjukkan beberapa dokumen yang berhasil dibuat di google document dan disimpan di google drive.

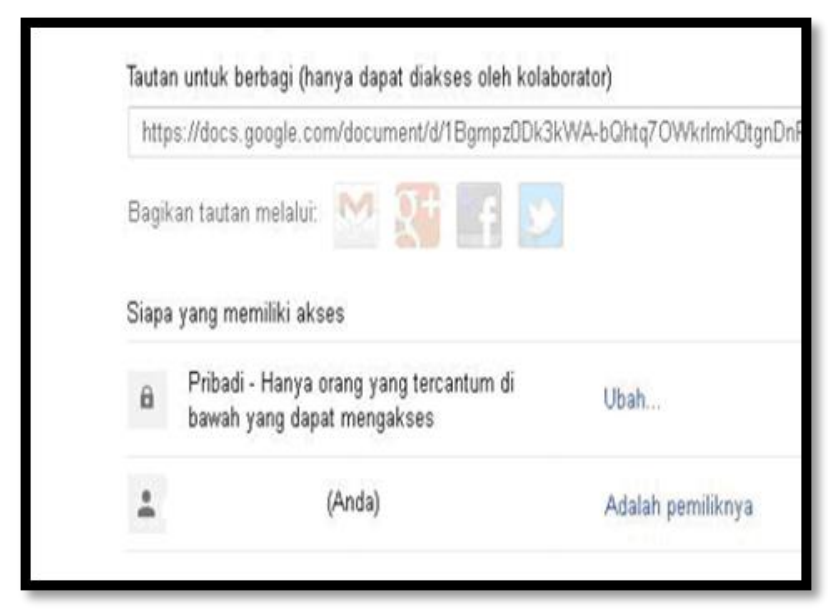

Gambar 3 Menunjukkan tautan link yang digunakan untuk berbagi. 


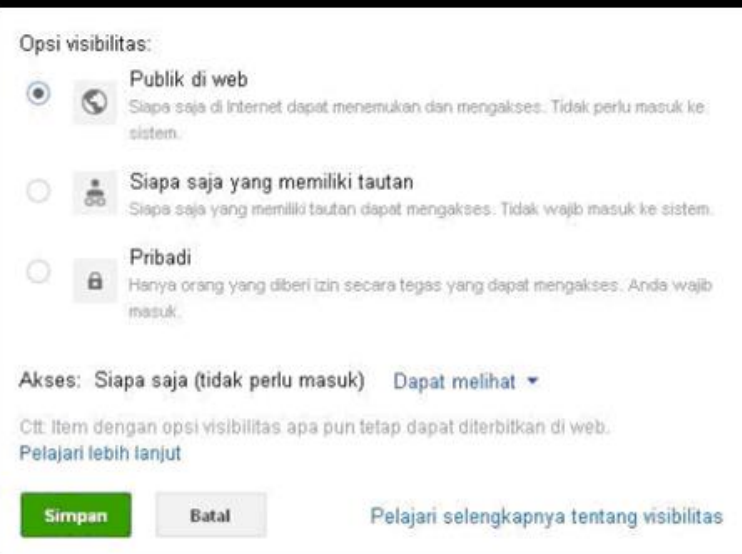

Gambar 4 Menampilkan halaman pemberian hak akses kepada user yang lainnya.

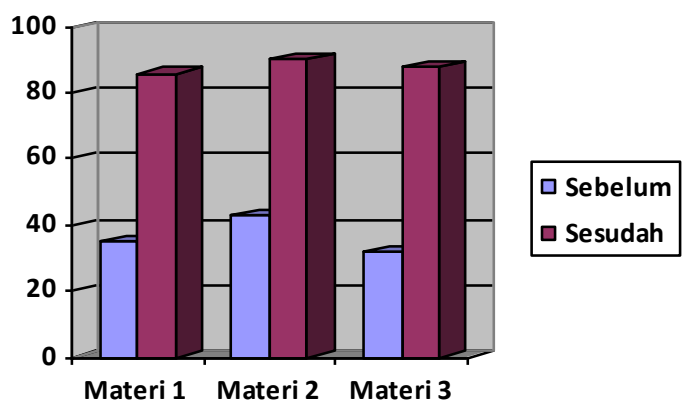

Gambar 5 Indikator keberhasilan pengabdian kepada menyarakat.

\section{Ucapan Terima Kasih}

Terima kasih disampaikan kepada pemberi dana pengabdian kepada masyarakat yaitu pimpinan Lembaga Penelitian Dan Pengabdian Kepada Masyarakat Universitas Putera Batam beserta jajarannya. Ucapan terima kasih juga disampaikan kepada Ketua RW 19 Pondok Rhabayu beserta jajarannya yang telah bersedia meluangkan waktu dan menerima kami serta membantu pelaksanaan pengabdian yang telah dilakukan.

\section{KESIMPULAN DAN SARAN}

\section{Kesimpulan}

Setelah melewati tahapan - tahapan yang telah ditetapkan sebelumnya maka dapat disimpulkan sebagai berikut :

1. Peserta pembinaan mampu dalam melakukan pemilihan Aplikasi office yang akan digunakan.
2. Peserta pembinaan mampu dalam melakukan pemilihan aplikasi penyimpanan yang sesuai.

3. Peserta pembinaan mampu dalam menggunakan aplikasi office berbasis cloud.

\section{Saran}

Pembinaan seperti ini sebaiknyanya dapat dilanjutkan, bukan hanya perangkat RW tapi lebih luas lagi secara ruang lingkup peserta ataupun bisa mencakup kepada objek yang lain.

Hasil kegiatan pengabdian masyarakat ini diharapkan untuk lebih dikembangkan untuk para dosen, agar tercipta sebuah hubungan positif dengan masyarakat melalui kerjasama yang baik dan saling menguntungkan dan paling utama berguna untuk masyarakat.

Perlu adanya proses evaluasi berkelanjutan untuk kegiatan ini agar tidak terjadi sebuah proses yang terputus yang telah dilaksanakan sebelumnya. Karena Pembinaan masyarakat ini pada akhirnya harus mendapatkan hasil atau target yang telah dibuat sebelumnya

\section{DAFTAR REFERENSI}

Fajrin, T. (2012). Analisis Sistem Penyimpanan Data Menggunakan Sistem Cloud Computing Studi Kasus Smk N 2 Karanganyar. IJNS, 1 (1), 32.

Purbo, O.,W. (2012). Membuat sendiri cloud computing server dengan menggunakan open source. Andi Offset. Yogyakarta.

Tutang. (2014) sistem operasi cloud computing dengan windows azure. Andi Offset. Yogyakarta.

Wahana Komputer. (2010). Seri Belajar Sekejap Google Docs, Olsh Dokumen Di Mana Saja. Andi Offset. Yogyakarta. 